\title{
ESCRITAS DOS PROFESSORES-CURSISTAS NA FORMAÇÃO CONTINUADA DE PROFESSORES: reflexão sobre dificuldades no manuseio de tecnologias no curso de extensão mídias na educação
}

\author{
Ângela Aparecida de Souto Silval
}

\section{RESUMO}

As Tecnologias da Informação e Comunicação (TIC) chegaram ao ambiente educacional, porém, ao utilizá-las, surgiram dificuldades no tocante ao desenvolvimento da formação continuada de professores. Diante dessa situação, o presente trabalho foi norteado pela seguinte questão: em que consistiram as dificuldades dos professores-cursistas do Curso de Extensão Mídias na Educação Ciclo Básico? Partindo desta questão, o objetivo geral foi conhecer as dificuldades apresentadas pelos professores-cursistas durante o Curso de Extensão Mídias na Educação - Ciclo Básico. Trata-se de um recorte de uma pesquisa mais ampla, do tipo descritiva, com abordagem qualitativa, intitulada O Diário de Bordo como recurso para reflexão crítica na formação docente no âmbito do Programa de Formação Continuada Mídias na Educação, desenvolvida no Mestrado Acadêmico em Educação, da Fundação Universidade Federal de Rondônia, no ano de 2016. Os dados advêm do Diário de Bordo, disponível no e-Proinfo. Foram sujeitos da pesquisa quatro professores-cursistas, do período de 2006-2007, tendo por lócus os polos de Porto Velho, Ji-Paraná e Vilhena, no estado de Rondônia, sudoeste da Amazônia brasileira. Os resultados apontaram que as dificuldades apresentadas são de natureza operacional, como: conexão lenta de internet, sites bloqueados e falta de tempo. Conclui-se que, apesar das dificuldades, há formas de superá-las a partir da reflexão sobre a situação no processo de formação do professor-cursista.

Palavras-chave: Tecnologias da informação e comunicação. Diário de bordo. Formação continuada.

\section{WRITINGS OF TEACHERS-CURSISTS IN CONTINUING TEACHER TRAINING: reflection on difficulties in handling technologies in the extension course media in education}

\footnotetext{
1 Mestre em Educação. Fundação Universidade Federal de Rondônia-UNIR, Porto Velho, Rondônia, Brasil. Orcid iD: https://orcid.org/0000-0002-9262-9337. E-mail: asouto@unir.br
} 


\section{ABSTRACT}

The Information and Communication Technologies (ICT) have reached the educational environment, but when using them, difficulties arose with regards to the development of continuing teachers' education. In view of this situation, the present work was guided by the following question: what were the difficulties of the teachertraining, of the Extension Course on Media in Education - Basic Cycle? Starting from this question, the general objective was to know the difficulties presented by the teacher-training during the Extension Course on Media in Education - Basic Cycle. This is an excerpt from a broader, descriptive research, with a qualitative approach, entitled The logbook as a resource for critical reflection in teacher education under the Continuing Education Program Media in Education, developed in the Academic Master in Education, from the Federal University of Rondônia Foundation, in 2016. The data come from the logbook, available on e-Proinfo. Four teacher training courses from the period 2006-2007 were the subjects of the research, with the locations of Porto Velho, Ji-Paraná and Vilhena, in the state of Rondônia, southwest of the Brazilian Amazon. The results showed that the difficulties presented are of an operational nature, such as: slow internet connection, blocked sites and lack of time. It is concluded that, despite the difficulties, there are ways to overcome them, based on the reflection about the situation in the teacher-training courses formation process.

Keywords: Information and Communication Technologies. Logbook. Continuing Education.

\section{ESCRITOS DE PROFESORES-ALUMNOS EN LA FORMACIÓN CONTINUA DE PROFESORES: reflexión sobre las dificultades en el manejo de las tecnologías en el curso de extensión de medios en educación}

\section{RESUMEN}

Las Tecnologías de la Información y la Comunicación (TIC) llegaron al entorno educativo, pero, al usarlas, surgieron dificultades con respecto al desarrollo de la formación continua del profesorado. En vista de esta situación, el presente estudio se guió por la siguiente pregunta: ¿̇cuáles fueron las dificultades de los profesoresalumnos del Curso de Extensión sobre Medios en Educación - Ciclo Básico? A partir de esta pregunta, el objetivo general era conocer las dificultades presentadas por los profesores-alumnos durante el Curso de Extensión sobre Medios en Educación Ciclo Básico. Este es un extracto de una investigación descriptiva más amplia, con un enfoque cualitativo, titulada El Libro de Registro como un recurso para la reflexión crítica en la formación del profesorado bajo el Programa de Educación Continua de Medios en Educación, desarrollado en el Máster Académico en Educación, de la Fundación de la Universidad Federal de Rondônia, en 2016. Los datos provienen del Libro de Registro, disponible en e-Proinfo. Cuatro profesoresalumnos del período 2006-2007 fueron los sujetos de la investigación, con las ubicaciones de Porto Velho, Ji-Paraná y Vilhena, en el estado de Rondônia, al suroeste de la Amazonía brasileña. Los resultados mostraron que las dificultades presentadas son de naturaleza operativa, tales como: conexión lenta a Internet, sitios bloqueados y falta de tiempo. Se concluye que, a pesar de las dificultades, hay formas de superarlas en función de la reflexión sobre la situación en el proceso de formación del profesor-cursista. 
Palabras clave: Tecnologías de la Información y la lomunicación. Libro de registro. Educación Continua.

\section{INTRODUÇÃO}

As Tecnologias da Comunicação e Informação (TIC) vêm promovendo grande dinamismo no modo como a sociedade age e modifica seu meio, oportunizando formas diferenciadas de construção de conhecimentos e atribuição de novos significados. Isso nos leva a refletir sobre as possibilidades das TIC serem inseridas no ambiente educacional, integrando-se ao fazer pedagógico.

Na década de 1990, o governo federal brasileiro, como fomentador de políticas públicas, buscou institucionalizar tais inovações por meio de documentos, entre eles o Plano Decenal de Educação 1993-2003 (BRASIL, 1993), a Lei de Diretrizes e Bases da Educação 9.394/1996 (BRASIL, 1999) e o Plano Nacional de Educação (BRASIL, 2001). Podemos identificar, em um dos seus dispositivos, que a formação de professores contemplou "o domínio de tecnologias de comunicação e da informação (TIC) e capacidade para integrá-las à prática docente" (BRASIL, 2001, p. 68). Também foi previsto equipar escolas com recursos tecnológicos para utilização pedagógica e desenvolvimento de programas de Educação a Distância (EAD) nos diferentes níveis de ensino (BRASIL, 2001).

Paralelamente a essas iniciativas, a formação de professores passou por transformações norteadas por algumas tendências. Uma delas, a tendência crítica, possibilita ao professor novos direcionamentos do seu fazer pedagógico, orientado pelo "paradigma da reflexão" (SCHÖN, 1983; ALARCÃO，1996; SCHÖN, 2000; FREIRE，2002; PERRENOUD，2002; PIMENTA, 2002; TARDIF, 2005).

Considerando esse cenário, foram implantados investimentos públicos na formação continuada de professores e recursos tecnológicos para as escolas brasileiras, mediante programas do governo federal, favorecendo o fomento de cursos na modalidade de EAD, com a utilização de diferentes 
meios midiáticos auxiliados pelos Ambientes Virtuais de Aprendizagem (AVA), como apoio aos cursos dessa modalidade de ensino.

Além disso, os recursos disponíveis no AVA podem auxiliar o professor na realização do processo reflexivo durante sua formação, tornando-se um caminho para contrapor o ensino baseado na transmissão-assimilação de conhecimentos. O Diário de Bordo é um desses recursos que, por intermédio da escrita, torna-se um dos meios para esse fim. Segundo Liberali (1999), o Diário de Bordo é uma ferramenta capaz de proporcionar mudanças no indivíduo, visto que o faz pensar de modo a promover a autoavaliação e perceber sua evolução.

No entanto, muitos percalços ocorrem durante o processo de formação de professores. Segundo Soares-Leite e Nascimento-Ribeiro (2012, p. 177), "um dos principais entraves para a utilização das TICs na educação brasileira é a falta de conhecimento e domínio dessas tecnologias por grande parte dos professores". Em seus estudos, os autores ressaltam a importância da formação como meio de propiciar embasamento para que o professor construa conhecimentos técnicos e pedagógicos acerca das tecnologias.

A partir desse contexto, apresentamos, neste artigo, um recorte de uma pesquisa mais ampla, do tipo descritiva, com abordagem qualitativa, intitulada O Diário de Bordo como recurso para reflexão crítica na formação docente no âmbito do Programa de Formação Continuada Mídias na Educação, desenvolvida no Mestrado Acadêmico em Educação da Fundação Universidade Federal de Rondônia (UNIR).

Como objeto de estudo, enfocamos as dificuldades encontradas pelos sujeitos da pesquisa durante a realização do curso de formação, considerando as reflexões feitas por esses participantes. Para a obtenção de dados, elegemos como fonte de pesquisa o Diário de Bordo, recurso on-line disponível no Ambiente Colaborativo de Aprendizagem e-Prolnfo, utilizado pelo Curso de Extensão Mídias na Educação - Ciclo Básico, no âmbito do Programa de Formação Continuada Mídias na Educação, ofertado pela Fundação Universidade Federal de Rondônia (UNIR) e desenvolvido em 
parceria com a Secretaria de Educação a Distância (SEED), atualmente extinta, e Secretarias de Educação (SE).

A questão que norteou nosso estudo foi: em que consistiram as dificuldades dos professores-cursistas do Curso de Extensão Mídias na Educação - Ciclo Básico? Partindo desta indagação, tivemos por objetivo geral conhecer as dificuldades apresentadas pelos professores-cursistas durante o Curso de Extensão Mídias na Educação - Ciclo Básico. Visando atingir nosso objetivo geral, propusemos como objetivos específicos: a) identificar quais as dificuldades apresentadas pelos professores-cursistas durante o Curso de Extensão Mídias na Educação - Ciclo Básico; e b) verificar se as dificuldades são de infraestrutura técnica, conhecimento pedagógico e domínio da tecnologia.

A organização deste artigo está assim disposta: iniciamos por esta introdução, na qual contextualizamos o problema. Continuando, abordamos - contexto teórico e descrevemos a metodologia adotada para a realização da pesquisa. Na sequência, procedemos a análise e interpretação dos dados, a partir dos textos contidos no Diário de Bordo. Por último, nas considerações finais, comentamos a respeito dos resultados obtidos.

\section{CONTEXTO TEÓRICO}

\section{A tecnologia e as implicações na educação}

A evolução tecnológica tende a predominar sobre as formas tradicionais de comportamento, modificando e estabelecendo novos processos de comunicação entre indivíduos e também a relação entre informação e aprendizagem (SILVA; CORREA, 2014).

Presente em nosso dia a dia, a "tecnologia é uma invenção do homem, produzida num determinado contexto social e cultural" (LÉVY, 1999, p. 25), impondo novos desafios que requerem conhecimento e formação permanente. 
No âmbito educacional, professores, alunos e escola são compelidos, por esse movimento, a buscar formas para se adequar à época atual. Em vista disso, surge a necessidade do professor experienciar e compreender as implicações educacionais que permeiam diferentes formas de lidar com a tecnologia, a fim de propiciar um ambiente criativo e reflexivo para o aluno. Assim, também inserida nesse contexto, a escola necessita reorganizar seu modelo de ensino, tornando-o prazeroso e contextualizado.

Nessa linha de pensamento, Altoé (2005) comenta que mudanças paradigmáticas ocorridas na sociedade trazem desdobramentos para a educação e para a escola, requerendo novos modelos de educação. Completando, o autor afirma que "o tipo de homem necessário para a sociedade de hoje é diferente daquele aceito em décadas passadas" (ALTOÉ, 2005, p. 39). Complementando, as autoras Corradini e Mizukami (2013) versam que as inovações são inadiáveis e que vão além de aquisição de habilidades, pois requerem uma nova forma de compreensão do Fazer pedagógico, com novos saberes, bem como uma formação permanente que visa preparar os professores para essa nova realidade da sala de aula.

Sob esse ponto de vista, Valente (1999) discute a inserção da informática na educação, discorrendo sobre a necessidade de alteração na proposta pedagógica, uma vez que o computador possibilita contribuições à aprendizagem. No entanto, é necessário pensar a reestruturação da constituição da escola, no sentido de estar receptível às inovações bem como à preparação do docente, para que este incremente, reinvente um fazer pedagógico diferenciado, de forma a viabilizar ao aluno a produção de seu conhecimento.

Tais demandas constituem-se em condição necessária à transformação do contexto educativo e das ações pedagógicas, já que não se restringem apenas à aquisição de diferentes recursos tecnológicos e sim instauram aspirações de profissionais engajados em formas diferenciadas para o ensino e a aprendizagem. Nessa perspectiva, Tornachi, Prado e Almeida (2010, p. 47) argumentam que: 
O uso da tecnologia na educação requer, sem dúvida, um olhar mais abrangente. Logo, é preciso que haja, nesse processo, o envolvimento de novas formas de ensinar, aprender e de desenvolver um currículo condizente com a sociedade tecnológica, que deve se caracterizar pela integração, complexidade e convivência com a diversidade de linguagens e formas de representar $o$ conhecimento.

Dialogando com os autores Valente (1999), Altoé (2005), Tornachi, Prado e Almeida (2010) e Corradini e Mizukami (2013), estes sinalizam para uma transformação no modelo educacional. Para tanto, é imprescindível introduzir mudanças na escola e na formação de professores, a fim de que a escola possa atender às necessidades de uma sociedade caracterizada pela tecnologia e conhecimento e os professores possam refletir sobre os resultados do seu fazer pedagógico. A consequência desse movimento tende a resultar em práticas balizadas pela reflexão, incorporando a tecnologia, numa perspectiva emancipadora e inovadora. Isso contribui na superação de uma cultura da assimilação e reprodução, a contar de um novo ambiente de ensino e aprendizagem.

Portanto, nesse processo, uma das prioridades diz respeito à formação de professores sob uma nova ótica, de modo contínuo, contextualizada nas práticas e voltada para um profissional reflexivo, conforme discutem os autores Nóvoa (1999); Schön (2000); Pérez Gómez (2002) e Tardif (2005), dentre os quais tomamos como referencial Schön (2000), para que essa assertiva possa ser concretizada.

\section{A formação continuada de professores: possibilidades de formação numa perspectiva reflexiva}

No campo da formação, identificamos um percurso em que há entendimentos diversificados e pautados por uma concepção tecnicista, cuja preocupação se volta ao êxito e à produtividade na educação. Nessa linha de raciocínio, nos deparamos com cursos rápidos, como os denominados de treinamento, reciclagem e capacitação, não considerando os saberes práticos dos professores, concebendo-os como meros receptores de conhecimento ou cumpridores de tarefas. Assim, a 
reflexão sobre práticas é deixada de lado, fortalecendo o desconhecimento da realidade do sujeito.

Durante um bom tempo, a preparação dos professores para o uso das tecnologias no fazer pedagógico consistiu em cursos aligeirados, num formato instrumental, sob a responsabilidade das secretarias de educação, visando atender ao programa oficial do governo, cabendo ao professor, em sala de aula, o desenvolvimento de atividades pontuais com a utilização de recursos tecnológicos e sem a possibilidade de refletir sobre a ação desenvolvida.

Mediante um contexto tecnológico, essa concepção de formação de professores torna-se inviável, requerendo a compreensão de que a tecnologia, como expressão da atividade humana e a serviço desta, faz parte da maneira de viver do ser humano. Desse modo, não conseguimos visualizar $\mathrm{o}$ homem separado da tecnologia. Concebemos que a necessidade de suplantar modelos convencionais por uma formação continuada fundamentada nas ideias de reflexão da prática - a qual se embasa nos conceitos de reflexão na ação, reflexão sobre a ação e reflexão sobre a reflexão na ação (SCHÖN, 2000) - pode ser uma possibilidade de preparar o professor para a inserção da tecnologia em seu fazer pedagógico.

As ideias de Schön (2000) apontam a premência da educação continuada a tentar para uma formação que integre os aspectos técnicos, práticos e a crítica, propiciando aos professores a reflexão na prática sobre suas práticas e sobre a reflexão de suas práticas. Essas reflexões promovem o diálogo sobre o observado e o vivido, com o objetivo de nortear a construção ativa do conhecimento na ação, pautada na metodologia do "aprender fazer fazendo", numa perspectiva de desenvolvimento profissional e pessoal.

Por esse viés, ressaltamos que a formação de professores críticos e reflexivos não ocorre por intermédio da inércia e da reprodução. Ela requer viver efetivamente o momento da formação, experienciando as etapas do processo, de forma a construir a aprendizagem. Assim, formar professores 
para a utilização da tecnologia, segundo Valente e Almeida (1997, p. 8), requer do profissional "[...] condições para que ele construa conhecimento sobre as técnicas computacionais, entenda por que e como integrar o computador na sua prática pedagógica e seja capaz de superar barreiras de ordem administrativa e pedagógica".

Segundo Valente e Almeida (1997), tomando por base tais aspectos, o profissional tende a romper com o modelo tecnicista transmitido pelas políticas públicas de formação de professores, abrindo caminho para propor mudanças no processo de ensino e de aprendizagem e, ainda, transpor dificuldades no âmbito administrativo (condições de infraestrutura física, materiais e técnicas, bem como o procedimento dos gestores escolares) e pedagógico. Por esse enfoque, Kenski (2007, p. 44) traduz que, para a superação das adversidades, se faz necessário

[...] buscar informações; realizar cursos, pedir ajuda aos mais experientes, enfim, utilizar os mais diferentes meios pra aprender a se relacionar com a inovação e ir além, começar a criar novas formas de uso e, daí, gerar outras utilizações. Essas novas aprendizagens, quando colocadas em prática, reorientam todos os nossos processos de descobertas, relações, valores e comportamentos.

A interlocução entre os autores Valente e Almeida (1997) e Kenski (2007) evidencia que a formação continuada é basilar para o professor, a fim de que este possa acompanhar as mudanças que estão ocorrendo na sociedade, evitando que a escola se torne descontextualizada desse processo.

Nesse sentido, Kenski (2007, p. 51) afirma que "cada vez mais, é preciso que haja uma nova escola, que possa aceitar o desafio da mudança e atender as necessidades de formação". Por essa vertente, Fullan e Hargreaves (2000) acrescentam que a escola também passa por um processo de aprendizagem, sendo compreendida como local em que se desenvolve uma organização aprendente, na medida em que seus professores progridem. 
Apesar das possibilidades de se implantar a utilização de recursos tecnológicos nas escolas, ainda nos deparamos com fragilidades e desafios. É o tema que trataremos a seguir.

\section{A conectividade na escola: possibilidades e desafios no uso da tecnologia}

Com a chegada do computador e da internet na escola, ocorreram novas oportunidades de exploração pedagógica. Inclui-se, nesse contexto, o ambiente virtual de aprendizagem, que congrega diferentes ferramentas, tais como fórum, diário de bordo, e-mail e chat, proporcionando novas interações entre professor-aluno, aluno-aluno e professor-aluno-aluno, construindo significados com suas trocas linguísticas por meio das escritas. Por essa lógica, Xavier (2005) reconhece que as ferramentas podem ser utilizadas no fazer pedagógico de forma a tornar as aulas de produção textual atraentes e dinâmicas, a título de exemplo.

Com relação ao chat, ferramenta síncrona de interação, podemos caracterizá-lo como um momento de ensino e aprendizagem fértil, desenvolvido coletivamente, constituindo-se como meio de gerar construção de conhecimento entre pessoas. Autores como Prado (2001), Mercado (2005) e Cruz (2006) defendem sua utilização no ensino e aprendizagem por entenderem que o chat propicia a instauração de uma rede interativa de desenvolvimento e construção do conhecimento em tempo real.

Entretanto, a utilização pedagógica do chat de forma crítica é um desafio, visto que há necessidade de "incentivar entre os professores o desenvolvimento de competências e habilidades necessárias para que possam atuar nesse novo ambiente, o que se estende às questões ligadas ao currículo e às práticas pedagógicas" (CGI.BR, 2016, p. 27).

Nessa vertente, Barbosa (2014, p. 293) expõe que a apropriação das tecnologias envolve "aspectos relacionados às capacidades e habilidades que permitem uma efetiva apropriação dessas ferramentas", uma dimensão mais complexa acerca da atuação docente e da intencionalidade do processo de ensino. 
Ainda por essa perspectiva, Almeida (2001 p. 43) alude que, ao se dispor a fazer uso das tecnologias, adotando metodologias inovadoras de aprendizagem, o professor "além de desenvolver a habilidade de uso das mesmas, estabelece uma ligação entre esse domínio, a prática pedagógica, as teorias educacionais, refletindo sobre sua própria prática buscando transformá-la". Isso pode resultar na dinamização e na intensificação do processo de ensino e aprendizagem.

Relacionando as ideias apresentadas por Almeida (2001), Barbosa (2014) e GI.BR (2016), identificamos que estas convergem para os dois aspectos: a) habilidade, saber fazer, saber lidar na prática com as tecnologias; e b) competência, "aprender a aprender", capacidade de mobilizar recursos e saberes vivenciados pela interação, a qual nos reporta à formação contínua para o uso das tecnologias - momento em que se reúnem saberes, atitudes e valores, envolvendo os domínios pessoal, cognitivo e comportamental de forma organizada e articulada (CRUZ, 2001).

No entanto, uma situação que precisa ser observada se refere à necessidade de investimentos em infraestrutura tecnológica e formação, pois, no processo de inovação, "os professores brasileiros demonstram interesse em utilizar recursos educacionais digitais, mas nem sempre existem condições de infraestrutura e capacitação para o uso da Internet com propósito pedagógico" (CGI.BR, 2015, p. 29).

A respeito da infraestrutura de conexão de internet, Barbosa (2014) reflete sobre a consequência da baixa velocidade nas escolas, vez que esta inviabiliza o suporte necessário ao desenvolvimento de atividades que requerem banda larga para trabalhar com os alunos em sala de aula. Lemos e Marques (2012) complementam, declarando que o problema tem origem na resistência de algumas empresas de telecomunicações em expandir o serviço de conexão de internet banda larga para áreas de regiões distantes, justificando a elevada carga tributária do Brasil e os altos custos de operação, dificultando que o usuário usufrua desses serviços. Lemos e Marques $(2012$, p. 8) acrescentam, ainda, que: 
Há evidências, ainda, de que a desigualdade se acentua se forem consideradas as diferenças de velocidade de conexão entre regiões. Ou seja, mesmo que tenham disposição em pagar mais caro pelo serviço, não há oferta de serviço por parte das operadoras em determinadas localidades.

Essa situação revela um desequilíbrio de velocidade e conexão de internet entre as regiões brasileiras, dado que nas localidades onde existem elevada densidade e maiores rendas, nas regiões Sudeste e Sul, a concorrência é acirrada entre as operadoras, que apostam na qualidade dos serviços diferenciados e com preços mais acessíveis. A região Norte fica em terceiro lugar, seguida das regiões Nordeste e Centro-Oeste (BOLAÑO; REIS, 2015), onde a situação é inversa: as operadoras não se sentem atraídas para a oferta de serviços.

A situação da infraestrutura de internet banda larga resulta do acordo realizado entre o governo federal e as empresas de telefonia, concedendo às mesmas exclusividades para implantar o cabeamento lógico nas cidades, até chegar às escolas, inicialmente gratuita até 2025 (BONILLA, 2010).

Tal exclusividade adquirida pelas empresas de telefonia acabou por refletir em altos preços cobrados aos usuários, principalmente nas localidades em que não há concorrência na prestação do serviço (BRASIL, 2009). Bonilla (2010, p. 48) sinaliza para a preocupação quanto à continuidade do projeto banda larga nas escolas após 2025, devido à indefinição na responsabilidade pela conexão nas escolas. A autora se refere ainda, a Brasil (2008), que menciona:

O programa Banda Larga nas Escolas faz parte da política do MEC para informatização das instituições de ensino, a qual prevê a instalação de computadores nas escolas, a capacitação de professores e a oferta de conteúdos educacionais. Entre as iniciativas estão o portal do Professor e do Banco Internacional de Objetos Educacionais destinados a auxiliar os professores na oferta de conteúdos curriculares com recursos de multimídia.

Bonilla (2010) se reporta à reformulação do Prolnfo, ocorrida pelo Decreto $n^{\circ}$ 6.300, de 12 de dezembro de 2007 (BRASIL, 2007a), contemplando a integração das mídias na educação com base na adoção de: a) 
infraestrutura com distribuição de computadores conectados à internet banda larga para as escolas urbanas e rurais; b) recursos de comunicação e interação entre professores e alunos pelo ambiente virtual de aprendizagem; e c) formação de professores para o uso de TIC na educação.

Essas proposições objetivam oferecer condições à escola e ao professor para que a tecnologia seja inserida no fazer pedagógico.

Trataremos, a seguir, do Programa de Formação Continuada Mídias na Educação.

\section{Programa de Formação Continuada Mídias na Educação - Ciclo Básico}

Visando atender metas estabelecidas no Plano de Desenvolvimento da Educação (PDE), o Programa Nacional de Informática na Educação (Prolnfo), criado pela Portaria $n^{\circ} 522$ (BRASIL, 1997), passou por uma reformulação, resultando no Decreto no 6.300 (BRASIL, 2007a), denominado de Programa Nacional de Formação Continuada em Tecnologia Educacional (Prolnfo Integrado). Dentre as finalidades deste programa, citase: promover o uso pedagógico das tecnologias e a formação dos agentes educacionais.

É nesse contexto que se institui, por meio da Portaria $n^{\circ} 171$ (BRASIL, 2007b) e da Resolução CD/FNDE n 64 (BRASIL, 2007c), o Programa de Formação Continuada Mídias na Educação, com a finalidade de formar profissionais atuantes na Educação Básica do sistema público de ensino para o uso integrado de diferentes mídias da informação e da comunicação (TV e vídeo, informática, rádio e impresso) no fazer pedagógico.

No ano de 2005, em caráter experimental, ocorreu o lançamento do programa pela Secretaria de Educação a Distância do Ministério da Educação (SEED/MEC), atualmente extinta. A organização do programa contemplou três ciclos de complexidade, com carga horária específica, caracterizando níveis de aprendizagem e certificação diferenciada: a) Ciclo Básico (Extensão)-120 horas; b) Intermediário (Aperfeiçoamento)-180 horas; e c) Avançado (Especialização)-mínimo de 360 horas. Sua estrutura modular, com sistemas de créditos, apresentou proposta integradora, articulada e 
autoral, sem perder de vista a reflexão-crítica quanto ao uso das mídias de forma consciente na escola.

A estrutura curricular do Ciclo Básico contemplou os módulos: Introdutório (30 horas), TV e Vídeo (15 horas), Rádio (15 horas), Informática (15 horas), Material Impresso (15 horas) e Gestão Integrada de Mídias (30 horas) (BRASIL, 2005).

O Curso de Extensão Mídias na Educação - Ciclo Básico foi desenvolvido pela Fundação Universidade Federal de Rondônia (UNIR), no período de 2006 a 2007, atendendo 211 professores-cursistas, distribuídos em quatro turmas, localizadas em três polos: Porto Velho (duas turmas), Ji-Paraná (uma turma) e Vilhena (uma turma), numa relação de, no mínimo, um tutor para cada 50 professores-cursistas.

No que diz respeito ao acompanhamento, em cada módulo foram realizados encontros presenciais, além de contar com $\circ$ Ambiente Colaborativo de Aprendizagem e-Prolnfo, plataforma virtual mantida pelo Ministério da Educação, a fim de hospedar o curso, disponibilizar os módulos (disciplinas) e propiciar a interação com seus diferentes recursos, como: a) apoio (agenda, referência, tira-dúvidas); b) interação (webmail); c) fórum; d) enquete; e) bate-papo (chat); f) diário de bordo; g) biblioteca (material do aluno, material do professor); e h) módulo (atividades do módulo, atividades da turma, conteúdo do módulo).

Dentre esses recursos, nos reportaremos, primacialmente, ao Diário de Bordo, por ser objeto deste estudo, como potencializador de práticas críticoreflexivas.

\section{Diário de Bordo: possibilidade de reflexão}

O Diário de Bordo, recurso assíncrono, disponibilizado no e-Prolnfo, possibilita ao aluno, ao longo do curso, o registro de suas experiências relativas aos avanços, dificuldades, dúvidas, questionamentos e anseios, resultantes do pensar sobre questões decorrentes dos procedimentos reflexivos a respeito do processo de aprendizagem. Nesse sentido, Freire (1996) menciona que "quando escrevemos desenvolvemos nossa 
capacidade reflexiva sobre o que sabemos e o que ainda não dominamos" (FREIRE, 1996, P. 6), a fim de compreender a realidade e orientar novos procedimentos para aprender.

Além de propiciar a reflexão crítica através da escrita, o Diário de Bordo é considerado como um recurso de aprendizagem e avaliação do processo de ensino e aprendizagem, conforme preconizam Pannunzio, Rizolli e Sanchez (2005, s/p.):

O Diário de Bordo acompanha os diferentes caminhos que o aluno percorre para realizar suas diferentes aprendizagens, ou seja: mobiliza recursos, ativa esquemas e toma decisões. Sendo assim, é uma avaliação processual, inclusiva e acolhedora; portanto, uma avaliação formativa, pois ajuda $o$ aluno a aprender e a se desenvolver a partir de um projeto educativo.

Os autores retratam que o uso do Diário de Bordo é um recurso que acompanha o aluno no seu processo de aprendizagem, como também favorece a organização de ideias, mediando métodos reflexivos para autoavaliação da aprendizagem, compreensão da realidade e orientação de novos procedimentos para aprender.

A seguir, abordaremos os procedimentos metodológicos utilizados para nortear a investigação do problema desta pesquisa.

\section{O DESENHO METODOLÓGICO DA PESQUISA}

A natureza do objeto de estudo nos levou a definir como metodologia a pesquisa empírica documental descritiva (LÜDKE; ANDRÉ, 2014), com abordagem qualitativa (BOGDAN; BIKLEN, 1994), tomando por base as escritas dos sujeitos e documentos primários que ainda não receberam nenhum tipo de tratamento, disponíveis no Diário de Bordo do e-Prolnfo, do curso de Extensão Mídias na Educação - Ciclo Básico, no período de 2006 a 2007, visando a obtenção de dados. Para a análise dos dados, consideramos a técnica de análise de conteúdos (BARDIN, 2011), buscando descrever o conteúdo das mensagens emitidas no processo de comunicação, alicerçada na temática categorial e subsidiada pelo 
referencial teórico. Neste caso, adotamos como temática categorial as dificuldades enfrentadas pelos participantes.

Participaram como sujeitos da pesquisa quatro professores-cursistas que atuaram, concomitantemente, como professores-tutores do curso. Para a preservação de suas identidades, foram denominados como ProfessorCursista (P1), Professor-Cursista (P2), Professor-Cursista (P3) e Professor-Cursista (P4), garantindo, dessa forma, o sigilo e o anonimato.

O campo empírico ficou delimitado aos sujeitos da pesquisa que estavam localizados nos polos de apoio presencial de Porto Velho, Ji-Paraná e Vilhena, no estado de Rondônia, sudoeste da Amazônia brasileira.

\section{AS PERCEPÇÕES DA ANÁLISE E DISCUSSÕES}

Para a análise, alicerçamos nossa pesquisa nos textos dos Diários de Bordo, disponíveis no e-Proinfo, como escritas elaboradas pelos professorescursistas, com a temática "reflexão sobre sua trajetória de aprendizagem", o que nos permitiu elencar como categoria a posteriori "Dificuldades Enfrentadas", conforme exposto no Quadro 1.

QUADRO 1 - Categoria "Dificuldades Enfrentadas", contendo fragmentos das escritas dos sujeitos da pesquisa P1, P2, P3 e P4

\begin{tabular}{|c|c|c|}
\hline $\begin{array}{c}\text { Categoria } \\
\text { a posteriori }\end{array}$ & $\begin{array}{c}\text { Sujeitos da } \\
\text { Pesquisa }\end{array}$ & $\begin{array}{c}\text { Fragmentos das escritas dos professores-cursistas } \\
\text { extraídas do Diário de Bordo }\end{array}$ \\
\hline \multirow{2}{*}{$\begin{array}{c}\text { Dificuldades } \\
\text { Enfrentadas }\end{array}$} & $\mathbf{P 2}$ & $\begin{array}{l}\text { "As dificuldades foram mais operacionais e consegui } \\
\text { superar com a ajuda da minha parceira de trabalho e } \\
\text { curso". } \\
\text { "Os obstáculos como, por exemplo, conexão lenta, sites } \\
\text { bloqueados e alguns trabalhos acumulados, devido não } \\
\text { conseguir conciliar e, alguns momentos trabalho e curso". }\end{array}$ \\
\cline { 2 - 3 } & $\mathbf{P 3}$ & $\begin{array}{l}\text { "Compreender os conteúdos não é tão difícil, já que } \\
\text { orientei os cursistas em todas as etapas, mas é o fator } \\
\text { tempo para elaborar uma boa reflexão pessoal escrita } \\
\text { avaliativa". } \\
\text { "Um dos maiores obstáculos tem sido a falta de tempo". }\end{array}$ \\
\hline
\end{tabular}

Fonte: Elaborado pelas autoras, 2016. 
Essa categoria se reporta às dificuldades encontradas pelos sujeitos da pesquisa (P1, P2, P3 e P4), no decorrer do curso, as quais se referem a problemas operacionais, conexão lenta, sites bloqueados e tempo exíguo para a realização das atividades previstas no módulo.

No que se refere aos problemas operacionais, estão relacionados ao manuseio dos recursos disponibilizados no e-Prolnfo para a postagem das atividades. Nesse sentido, Valente (2005, p. 30-31) considera que:

\begin{abstract}
Embora as sofisticações tecnológicas sejam ainda maiores, existem dois aspectos que devem ser observados na implantação dessas tecnologias na educação. Primeiro, o domínio do técnico e do pedagógico não deve acontecer de modo estanque, um separado do outro. É irrealista pensar em primeiro ser um especialista em informática ou em mídia digital para depois tirar proveito desse conhecimento nas atividades pedagógicas. O melhor é quando os conhecimentos técnicos e pedagógicos crescem juntos, simultaneamente, um demandando novas ideias do outro. O domínio das técnicas acontece por necessidades e exigências do pedagógico e as novas possibilidades técnicas criam novas aberturas para o pedagógico, constituindo uma verdadeira espiral de aprendizagem ascendente na sua complexidade técnica e pedagógica.
\end{abstract}

Tornaghi, Prado e Almeida (2010, p. 51) comentam que:

O professor que associa as TICs aos métodos ativos de aprendizagem é aquele que também busca desenvolver a habilidade técnica relacionada ao domínio da tecnologia e, sobretudo, esforça-se para assumir uma atitude de reflexão frequente e sistemática sobre sua prática, sobre o que seus pares falam da própria prática e sobre as teorias tratadas por autores de referência.

Os autores compreendem que a inviabilidade técnica não é empecilho para a realização do curso, dado que os obstáculos vão desaparecendo no decorrer dos estudos, na medida em que vamos manuseando os recursos existentes, junto com a aprendizagem pedagógica. Além disso, o auxílio de colegas contribui muito para facilitar a aprendizagem técnica; a exemplo, o sujeito Pl relatou, em seus escritos, que superou sua dificuldade com a ajuda de uma parceira de trabalho. A esse espeito, Kenski (1996, p. 146) argumenta que: 
A aprendizagem pode se dar com o envolvimento integral do indivíduo, isto é, do emocional, do racional, do seu imaginário, do intuitivo, do sensorial em interação, a partir de desafios, da exploração de possibilidades, do assumir de responsabilidades, do criar e do refletir juntos.

A aprendizagem é um processo ativo que conduz a transformações e a diferentes formas de superar obstáculos, dentre elas a de refletir juntos. Almeida (2003, p. 335) expõe que "aprender é planejar; desenvolver ações; receber, selecionar e enviar informações; estabelecer conexões; refletir sobre o processo em desenvolvimento com os pares".

Neste caso, Pl buscou interagir com seus pares e adquirir domínio para o manuseio dos recursos tecnológicos no processo de construção de sua aprendizagem.

Com relação à conexão lenta, abordada por P3, sabemos que, em certas regiões do interior do Brasil, a conexão de internet apresenta fragilidade, especialmente na região Norte, pela dimensão de seu território e em virtude de parte da área ser coberta por uma densa floresta e rios. Desse modo, como um dos grandes desafios ao acesso à internet, encontram-se também questões de intempéries, como chuvas e ventos. Além do mais, há casos em que a sobrecarga de acessos simultâneos inviabiliza o sinal, ou este é mínimo, dificultando fazer download e upload, o que é caracterizado por Lévy (1999) como "dilúvio informacional".

Por essa ótica, Barbosa (2014, p. 29) avalia que, "apesar de avanços verificados nos últimos anos, a velocidade de conexão ainda é uma das principais barreiras, especialmente se considerada a necessidade de uso simultâneo de equipamentos em uma mesma escola". Colaborando com essa discussão, Lemos e Marques (2012) alegam que no Brasil há poucas prestadoras de serviços de internet de banda larga localizadas no Norte e Nordeste, especialmente operando no interior dessas regiões. Tal afirmação evidencia a necessidade de se ampliar o quantitativo dessas operadoras, no intento de reduzir disparidades no atendimento de serviço de internet banda larga nas regiões descobertas e, com isso, ampliar a velocidade de 
conexão, a fim de que se possa trabalhar em melhores condições tecnológicas.

No que diz respeito a site bloqueado, mencionado por P3, a Secretaria de Estado da Educação de Rondônia adotou o bloqueio de sites, durante o Curso de Extensão Mídias na Educação - Ciclo Básico (2006 a 2007), como medida necessária à proteção de rede, dos computadores e seus usuários, para evitar problemas relacionados à segurança de dados. Com isso, houve dificuldades no desenvolvimento de atividades quando se utilizou, na ocasião, mensagem, chat, facebook, Orkut. Tal situação se tornou inconveniente tanto para os professores-cursistas, que estavam em processo de formação, quanto para seus respectivos alunos, pois impossibilitou os professores-cursistas de utilizarem esses recursos tecnológicos no fazer pedagógico.

Embora haja restrições a recursos síncronos, autores como Prado (2001), Mercado (2005) e Cruz (2006) defendem o seu uso como, por exemplo, o chat, vislumbrando o ensino e aprendizagem, uma vez que esse recurso possibilita a comunicação entre pessoas separadas em espaço e tempo, de forma que possam manter diálogo em tempo real.

A falta de tempo, retratada por P4, deve-se à sobrecarga de trabalho imposta ao professor, configurando-se como dificuldade para a sua formação e apropriação das tecnologias em seu fazer pedagógico. Uma alternativa proposta por Fullan e Hargreaves (2000, p. 51) sobre a questão do tempo diz respeito à compreensão dos diretores e vice-diretores de escola, os quais

[...] podem também auxiliar, liberar tempo ao professor para outras atividades, dando, ocasionalmente, cobertura às suas aulas. Assim, agindo, eles também mostram seu compromisso com a atividade para a qual os professores estão sendo liberados.

Os autores Fullan e Hargreaves (2000) destacam a importância de reagirmos frente às dificuldades, procurando identificar suas origens e buscar soluções, de modo a possiblitar o crescimento e o aperfeiçoamento pessoal 
e profissional do professor. Isso propiciará desenvolver a criatividade e desprendimento para iniciativas inovadoras.

\section{CONSIDERAÇÕES FINAIS}

Ao concluirmos este trabalho, retomamos o seu objetivo geral, que foi conhecer as dificuldades apresentadas pelos professores-cursistas durante 0 Curso de Extensão Mídias na Educação - Ciclo Básico. Para alcançar sua finalidade, contamos com dois objetivos específicos, resgatados a seguir.

O primeiro centra-se na identificação das dificuldades apontadas pelos professores-cursistas durante 0 curso e 0 segundo verifica se as dificuldades estão relacionadas aos aspectos de infraestrutura técnica, conhecimento pedagógico ou domínio da tecnologia.

No tocante ao primeiro objetivo, nos fragmentos extraídos das escritas dos professores-cursistas P1, P2, P3 e P4, sujeitos da pesquisa, identificamos que as dificuldades vivenciadas estão relacionadas às questões operacionais (alusivas ao manuseio dos recursos disponibilizados no eProlnfo), bloqueio de sites, conexão lenta e falta de tempo para os estudos.

No que diz respeito ao segundo objetivo - verificar se as dificuldades estão relacionadas aos aspectos de infraestrutura técnica, conhecimento pedagógico ou domínio da tecnologia - averiguamos que as dificuldades operacionais se relacionam aos aspectos de domínio da tecnologia, sendo necessário adquirir conhecimento para se chegar à alfabetização digital.

As dificuldades pertinentes a bloqueio de sites e conexão lenta estão vinculadas à infraestrutura técnica, visto que há uma precarização de investimentos dessa natureza por parte do poder público. Relativamente à falta de tempo, decorre de fator como a sobrecarga de trabalho que é imposta ao professor.

Apesar das dificuldades atinentes às questões operacionais, tais como bloqueio de sites, conexão lenta e falta de tempo, há formas de superá-las ou, pelo menos, minimizá-las, a partir da reflexão sobre a situação no processo de formação dos professores, com suas percepções no que diz 
respeito à importância das tecnologias como recursos que oportunizam mudanças e auxiliam na construção do conhecimento em sala de aula.

\section{REFERÊNCIAS}

ALARCÃO, I. (Org.). Formação reflexiva de professores: estratégias de supervisão. Porto, Portugal: Porto Editora, 1996.

ALMEIDA, M. E. B. Educação, projetos, tecnologia e conhecimento. São Paulo: PROEM, 2001.

ALMEIDA, M. E. B. Educação a distância na Internet: abordagens e contribuições dos ambientes digitais de aprendizagem. Educação e Pesquisa. São Paulo, v. 29, n. 2, p. 327-340, 2003.

ALTOÉ. A. O desenvolvimento da informática aplicada no Brasil. In: ALTOÉ, A. O.; COSTA, M. L. F. A.; TERUYA, T. K. (Orgs.). Educação e Novas Tecnologias. Maringá: EDUEM, 2005, v. 1, p. 39-53.

BARBOSA, A. F. Pesquisa sobre o uso das tecnologias da informação e comunicação nas escolas brasileiras. Comitê Gestor da internet (livro eletrônico), 2014.

BARDIN, L. Análise de Conteúdo. São Paulo: Edições 70, 2011.

BOGDAN, R.; BIKLEN, S. Investigação qualitativa em educação: uma introdução à teoria e aos métodos. Porto, Portugal: Porto Editora, 1994.

BOLAÑO, C. R. S.; REIS, D. A. Banda larga, cultura e desenvolvimento. Nova Economia. Belo Horizonte, v. 24, n. 2, p. 387-402, 2015.

Disponível em: <http://www.scielo.br/pdf/neco/v25n2/1980-5381-neco-25-0200387.pdf>. Acesso em: 20 mar. 2017.

BONILLA, M. H. S. Políticas públicas para inclusão digital nas escolas - doi: 10.5007/2175-8042.2010n34p40. Motrivivência. Florianópolis, n. 34, p. 40-60, 2010. Disponível em:

<https://www.periodicos.ufsc.br/index.php/motrivivencia/article/view/17135/ 15840>. Acesso em: 10 mar 2017.

BRASIL. Ministério da Educação. Plano decenal de educação para todos. Brasília, 1993.

BRASIL. Ministério da Educação e do Desporto. Portaria n. 522, de 9 de abril de 1997. Cria o Programa Nacional de Informática na Educação. Disponível em: <http://www.dominiopublico.gov.br/download/texto/me001167.pdf>. Acesso em: 20 mar 2017. 
BRASIL. LDB: Lei de Direrizes e Bases da Educação. Lei n. 9.394/96. 2.ed., Rio de Janeiro, DP\&A, 1999.

BRASIL. Ministério da Educação e do Desporto. Instituto Nacional de Estudos e Pesquisas Educacionais. Plano nacional de educação 2001. Disponível em: <http://www.portal.inep.gov.br/documents/186968/484184/Plano+Nacional+ de+Educa\%C3\%A7\%C3\%A3o+proposta+do+Executivo+ao+Congresso+Nacio $\mathrm{nal} / 3 f 4 d 496 \mathrm{~d}-17 \mathrm{c} 6-4 \mathrm{a} 89-83 \mathrm{e} 4-8 \mathrm{ebc5bcc86de}$ ?version=1.1 >. Acesso em: 15 abr 2017.

BRASIL. Ministério da Educação. Secretaria de Educação a Distância. Projeto básico do programa de formação continuada mídias na educação. Brasília, 2005, p. 11-28.

BRASIL. Decreto n. 6300, de 13 de dezembro de 2007. Dispõe sobre o Programa Nacional de Tecnologia Educacional - Prolnfo. Diário Oficial da União, Brasília/DF, n. 239, p. 3, 13 dez. 2007a. Secção 1. Disponível em: $<\mathrm{http}$ ///www.pesquisa.in.gov.br/imprensa/jsp/visualiza/index.jsp?jornal=1 \&pa gina=3\&data=13/12/2007>. Acesso em: 10 mar 2017.

BRASIL. Ministério da Educação. Secretaria de Educação a Distância. Portaria $n^{\circ} 171$, de 16 de outubro de 2007. Institui o programa de Formação Mídias na Educação. Diário Oficial da União, Brasília/DF, seção 1, 2007b.

BRASIL. Ministério da Educação. Secretaria de Educação a Distância. Resolução n 064, de 13 de dezembro de 2007. Estabelece critérios e procedimentos para participação de instituições públicas de ensino superior na implementação do Programa de Formação Continuada Mídias na Educação. Brasília/DF: 2007c.

BRASIL. Ministério da Educação. Mais escolas terão internet banda larga. 2008. Disponível em: <http://portal.mec.gov.br/ultimas-noticias/210$1448895310 / 11712-\mathrm{sp}-$ 2068415360?sa=X\&ved=2ahUKEwjpv92_4_nAhWNJrkGHeB5BICQFjAAegQIABA B>. Acesso em: 20 mar 2017.

BRASIL. Câmara dos Deputados. Alternativas de políticas públicas para a banda larga. Relator: LUSTOSA P. H.; PAZ FILHO; J. S. (Coords.). Série Caderno de Altos Estudos. Brasília, n. 6, 2009.

CGI.BR. Pesquisa sobre o uso das tecnologias da informação e comunicação nas escolas brasileiras TIC educação 2014. Coordenação executiva Barbosa, A. F., São Paulo: Comitê Gestor da Internet no Brasil (livro eletrônico), 2015. 
CGI.BR. Pesquisa sobre o uso das tecnologias da informação e comunicação nas escolas brasileiras TIC educação 2015. Coordenação executiva Barbosa, A. F., São Paulo: Comitê Gestor da Internet no Brasil (livro eletrônico), 2016.

CORRADINI, S. N.; MIZUKAMI, M. G. N. Práticas pedagógicas e o uso da informática. Revista Exitus, v. 3, n. 2, p. 85-92, 2013.

CRUZ, C. H. C. Competências e habilidades: da proposta à prática. São Paulo: Edições Loyola, 2001.

CRUZ, W. B. Experiências utilizando ferramentas síncronas na educação. In: MERCADO, L. P. L. (Org.). Experiências com tecnologias da informação e comunicação na educação. Maceió: EDUFAL, 2006.

FREIRE, M. Observação, registro, reflexão-instrumentos metodológicos I. 2.ed., São Paulo: Espaço Pedagógico, 1996.

FREIRE, P. Pedagogia da autonomia. 21.ed., Rio de Janeiro: Paz e Terra, 2002.

FULLAN, M.; HARGREAVES, A. A escola como organização aprendente: buscando uma educação de qualidade. 2.ed., Porto Alegre: Artes Médicas Sul, 2000.

KENSKI, V. M. O Ensino e os recursos didáticos em uma sociedade cheia de tecnologias. In. VEIGA, I. P. A. (Org.). Didática: o ensino e suas relações. Campinas: Papirus, 1996.

KENSKI, V. M. Educação e tecnologias: o novo ritmo da informação. 2.ed., Campinas: Papirus, 2007.

LEMOS, A.; MARQUES, F. P. J. A. O Plano Nacional de Banda Larga Brasileiro: um estudo de seus limites e efeitos sociais e políticos. E-Compós. Brasília, v. 15, p. 1-26, 2012. Disponível em: <http://www.compos.org.br/seer/index.php/ecompos/article/viewFile/765/573>. Acesso em: 15 set. 2016.

LÉVY, P. Cibercultura. São Paulo: Editora 34, 1999.

LIBERALI, F. C. O diário como ferramenta para reflexão crítica. 1999. $166 f$. (Tese de Doutorado) - Pontifícia Universidade Católica de São Paulo, SP, 1999.

LÜDKE, M. A. M.; ANDRÉ, E. D. A. Pesquisa em educação: abordagens qualitativas. 2.ed., São Paulo: EPU, 2014.

MERCADO, L. P. L. Vivências com aprendizagem na internet. Maceió: EDUFAL, 2005. 
NÓVOA, A. La nueva cuestión central de los profesores: exceso de discursos, probreza de prácticas. Cuadernos de Pedagogía. Barcelona, n. 286, p. 102108, 1999.

PANNUNZIO, M. I. M.; RIZOLLI, M.; SANCHEZ, P. S. O diário de bordo como instrumento de aprendizagem e avaliação no processo de educação pela arte. In: REUNIÃO ANUAL DA SBPC, 57, 2005, Fortaleza. Anais. Disponível em: <http://www.sbpcnet.org.br/livro/57ra/programas/senior/RESUMOS/resumo_3 139.html>. Acesso em: 10 mar 2017.

PÉREZ GÓMEZ, A. I. La función y formación del profesor/a en la enseñanza para la comprensión: diferentes perspectivas. In: SACRISTÁN, J. G.; PÉREZ GÓMEZ, A. I. Comprender y transformar la enseñanza. Madrid: Ediciones Morata, 2002, p. 398-429.

PERRENOUD, P. A prática reflexiva no ofício de professor: profissionalização e razão pedagógica. Porto Alegre: Artmed, 2002.

PIMENTA, S. G.; CHEDIN, E. (Orgs.). Professor reflexivo no Brasil: gênese e crítica de um conceito. 2. ed., São Paulo: Cortez, 2002.

PRADO, M. E. B. B. Educação a distância: os ambientes virtuais e algumas possibilidades pedagógicas. Salto para futuro/SEED/MEC. Brasília, DF: MEC/SEED, 2001.

SCHÖN, D. A. The reflective practitioner: how professionals think in action. London: Temple Smith, 1983.

SCHÖN, D. A. Educando o profissional reflexivo: um novo design para o ensino e a aprendizagem. Porto Alegre: Artmed, 2000.

SILVA, R. F.; CORREA, E. S. Novas Tecnologias e Educação: a evolução do processo de ensino e aprendizagem na sociedade contemporânea.

Educação \& Linguagem. Ano 1, n. 1, p. 23-35, 2014.

SOARES-LEITE, W. S.; NASCIMENTO-RIBEIRO, C. A. A inclusão das TICs na educação brasileira: problemas e desafios. Magis - Revista Internacional de Investigación en Educación, v. 5, n. 10, p. 173-187, 2012.

TARDIF, M. Saberes docentes e formação profissional. 5.ed., Petróplolis: Vozes, 2005.

TORNACHI, A. J. C.; PRADO, M. E. B. B.; ALMEIDA, M. E. B. Tecnologias na educação: ensinando e aprendendo com as TIC: guia do cursista. 2.ed., Brasília: Secretaria de Educação a Distância, 2010. 
VALENTE, J. A. Informática na educação no Brasil: análise e contextualização histórica. In: VALENTE, J. A. (Org.). O computador na sociedade do conhecimento. Campinas: UNICAMP/NIED, 1999, p. 1-13.

VALENTE, J. A. O papel do computador no processo ensino-aprendizagem. In: ALMEIDA, M. E. B.; MORAN, J. M. (Orgs.). Integração das tecnologias na educação. Brasília: SEED/MEC, 2005, p.31-46. Disponível em:

<http://livros01 livrosgratis.com.br/me000701.pdf>. Acesso em: 15 abr 2017.

VALENTE, J. A.; ALMEIDA, F. J. Visão analítica da informática na educação no Brasil: a questão da formação do professor. Revista Brasileira de Informática na Educação. Florianópolis, v. 1, 1997.

XAVIER, A. C. Gêneros textuais emergentes no contexto da tecnologia digital. In: MARCUSCHI, L. A.; XAVIER, A. C. (Orgs.). Hipertexto e gêneros digitais: novas formas de construção de sentido. 2.ed., Rio de Janeiro: Lucerna, 2005, p.13-67.

Recebido em: 28 de agosto de 2020

Aprovado em: 19 de outubro de 2020 Publicado em: 01 de dezembro de 2020 